\title{
Penggunaan ASEAN Way dalam Upaya Penyelesaian Sengketa Laut Tiongkok Selatan: Sebuah Catatan Keberhasilan?
}

\author{
Arief Bakhtiar Darmawan ${ }^{1}$, Hestutomo Restu Kuncoro ${ }^{2}$ \\ ${ }^{1}$ International Relations, Universitas Jenderal Soedirman, Indonesia \\ ${ }^{2}$ International Relations, Mancester University England
}

\begin{tabular}{l}
\hline ARTICLE INFORMATION \\
\hline \\
\hline SUBMISSION TRACK \\
\hline Recieved :07, February, 2019 \\
Final Revision : 20, May, 2019 \\
Available Online: 30, May, 2019 \\
\hline KEYWORD \\
\hline Indonesia environmental diplomacy, greening \\
ASEAN Way, peat restoration agency, English \\
School
\end{tabular}

\begin{abstract}
Up to this point, the principles in ASEAN Way have been challenged by the regional dynamics of Southeast Asia. This article seeks to observe ASEAN's efforts in handling the resolution of the South China Sea (SCS) dispute and the failure of the ASEAN Way to adequately support the effort. To do so, the writers use a qualitative method which relies on academic literature regarding SCS and ASEAN's official documents to comprehend, interpret, and to formulate the result of the research. This article uses the perspective of constructivism which provides the structure to explain the normative drives behind the actions of International actor. Based on the analysis, ASEAN Way is a positive drive to dialogues and peaceful consultations but not in itself a solution to end the dispute. The Way had allowed ASEAN to become central in the peaceful resolution efforts involving major powers from beyond the region. ASEAN Way, however, has its back draws; one of which was used by China to prevent ASEAN's intervention in or to dictate policy regarding the SCS dispute. Therefore, ASEAN collectivity in handling the SCS dispute should be the next step forward.
\end{abstract}

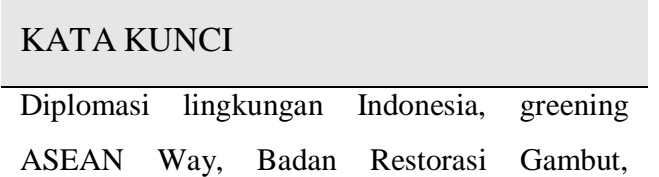

English School

CORRESPONDENCE

E-mail: ariefbakhtiar@ rocketmail.com

\begin{tabular}{l} 
ABSTRAK \\
\hline Sampai saat ini, prinsip-prinsip dalam ASEAN Way selalu \\
mendapatkan tantangan dalam menghadapi dinamika \\
kawasan Asia Tenggara. Artikel ini bertujuan untuk \\
mengamati upaya-upaya ASEAN dalam menangani \\
penyelesaian sengketa Laut Tiongkok Selatan dan mengapa \\
ASEAN Way gagal memengaruhi upaya-upaya tersebut \\
secara optimal. Untuk menjawab rumusan tersebut, penulis \\
menggunakan metode penelitian kualitatif yang \\
mengandalkan literatur-literatur akademis mengenai LTS \\
dan dokumen-dokumen resmi ASEAN untuk memahami, \\
menginterpretasikan, serta menyusun hasil penelitian dari
\end{tabular}

Sampai saat ini, prinsip-prinsip dalam ASEAN Way selalu mendapatkan tantangan dalam menghadapi dinamika kawasan Asia Tenggara. Artikel ini bertujuan untuk mengamati upaya-upaya ASEAN dalam menangani penyelesaian sengketa Laut Tiongkok Selatan dan mengapa ASEAN Way gagal memengaruhi upaya-upaya tersebut secara optimal. Untuk menjawab rumusan tersebut, penulis menggunakan metode penelitian kualitatif yang mengandalkan literatur-literatur akademis mengenai LTS menginterpretasikan, serta menyusun hasil penelitian dari 


\begin{abstract}
fenomena sengketa LTS. Penulis menggunakan perspektif konstruktivisme yang menyediakan struktur normatif untuk menjelaskan tindakan politik aktor internasional. Berdasarkan analisis terhadap data dan pembahasan, ASEAN Way merupakan pendorong yang positif dalam konteks fungsi dialog dan konsultasi damai dan bukan sebagai solusi untuk penyelesaian sengketa LTS. ASEAN berhasil menjadi sentral dalam upaya penyelesaian damai yang juga melibatkan negara-negara besar luar kawasan. Untuk menjadi sebuah solusi nyata, ASEAN Way masih memiliki tantangan karena seringkali menjadi alat Tiongkok agar ASEAN tidak melakukan intervensi atau pemaksaan kebijakan suatu negara terkait penyelesaian konflik LTS. Oleh karena itu, kolektivitas ASEAN dalam menghadapi isu LTS merupakan langkah ke depan yang perlu untuk segera diwujudkan.
\end{abstract}

\section{Pendahuluan}

Beberapa pengamat melihat kesuksesan Association of Southeast Asian Nations (ASEAN) menjaga keamanan dan stabilitas kawasan dalam konteks peran norma-norma ASEAN, seperti penggunaan cara-cara non-kekerasan, non-intervensi, dan pertemuan informal sebagai bagian dari manajemen konflik. ${ }^{1}$ Stabilitas itulah yang saat ini membuat negara-negara ASEAN bisa fokus pada pembangunan dalam negeri dan mengupayakan kesejahteraan ekonomi. Namun, sepanjang perjalanannya sebagai organisasi regional, ASEAN tidak lepas dari kritik. Kontribusi ASEAN dalam lingkup regional, misalnya, masih dianggap minim. ${ }^{2}$ Prinsip non-intervensi yang dipegang

\footnotetext{
${ }^{1}$ Lihat, Timo Kivimäki, "The Long Peace of ASEAN," Journal of Peace Research 38, no. 1 (2001): 5-25; Nikolas Busse, "Constructivism and Southeast Asian security," The Pacific Review 12, no. 1 (1999): 39-60; Mely Caballero-Anthony, "Mechanism of Dispute Settlement: The ASEAN Experience," Contemporary Southeast Asia 20, no. 1 (1998): 38-66.

${ }^{2}$ Mark Beeson, "What's the point of Asean?" Asia Times, 1 Mei 2017, http://www.atimes.com/whatspoint-asean/ (diakses pada 28 November 2018).
}

ASEAN dipandang tidak cukup mampu dalam menangani krisis pengungsi Rohingya dan mengatasi pelanggaran hak asasi manusia dalam konflik Timor LesteIndonesia. ${ }^{3}$ Langkah-langkah ASEAN dalam menjalin relasi dengan rezim militer yang tidak demokratis di antara anggotanya juga dinilai terlalu lembek oleh Barat. ${ }^{4}$ Persoalan kesatuan dan keaktifan ASEAN dalam isuisu yang sulit dan kontroversial masih menjadi bahasan yang relevan untuk terus diperbincangkan, termasuk dalam isu Laut Tiongkok Selatan (LTS). Pandangan dan sikap negara-negara ASEAN masih terbelah dalam menghadapi isu LTS ini. ${ }^{5}$

Laut Tiongkok Selatan merupakan area perairan yang terbentang sepanjang 1.100 kilometer dari Selat Malaka di barat

\footnotetext{
${ }^{3}$ Tony Firman, "Disfungsi ASEAN dan Kegagapannya Merangkul Asia Tenggara," Tirto.id, 8 Agustus 2018, https://tirto.id/disfungsi-asean-dankegagapannya-merangkul-asia-tenggara-cP9S (diakses pada 3 Desember 2018).

${ }^{4}$ Iwao Fujisawa, "The Use and Abuse of the ASEAN Way" (Discussion Papers, Chiba University, 2017).

5 Arief Bakhtiar Darmawan \& Lady Mahendra, "Isu Laut Tiongkok Selatan: Negara-negara ASEAN Terbelah Menghadapi Tiongkok," Jurnal Global \& Strategis 12, no. 1 (2018): 79-100.
} 
daya hingga ke Selat Taiwan di timur laut (lihat gambar 1). Daerah ini telah lama diprediksi akan menjadi daerah konflik karena posisi geografis dan geopolitiknya yang strategis. ${ }^{6}$ LTS diperkirakan memiliki sebelas miliar barel minyak bumi, lima triliun meter kubik gas alam, serta satu-persepuluh populasi ikan dunia hidup di LTS. Selain memiliki potensi ekstraktif, LTS juga merupakan jalur strategis perdagangan yang dilewati oleh komoditi senilai $\$ 5,3$ triliun setiap tahunnya. Posisi LTS yang strategis juga membuatnya menjadi lokasi ideal untuk pangkalan militer. Tiongkok sendiri telah memanfaatkan beberapa pulau di LTS sebagai dermaga transit untuk angkatan laut mereka, tindakan yang membuat khawatir negara-negara di sekitar LTS. Selain negara sekitar LTS, negara-negara yang jauh secara geografis seperti Australia, India, Jepang, dan Amerika Serikat (AS) juga telah menyatakan rencana mereka melakukan patroli militer di wilayah LTS. ${ }^{7}$

\section{Gambar 1.}

Peta Tumpang Tindih Klaim di Laut Tiongkok Selatan

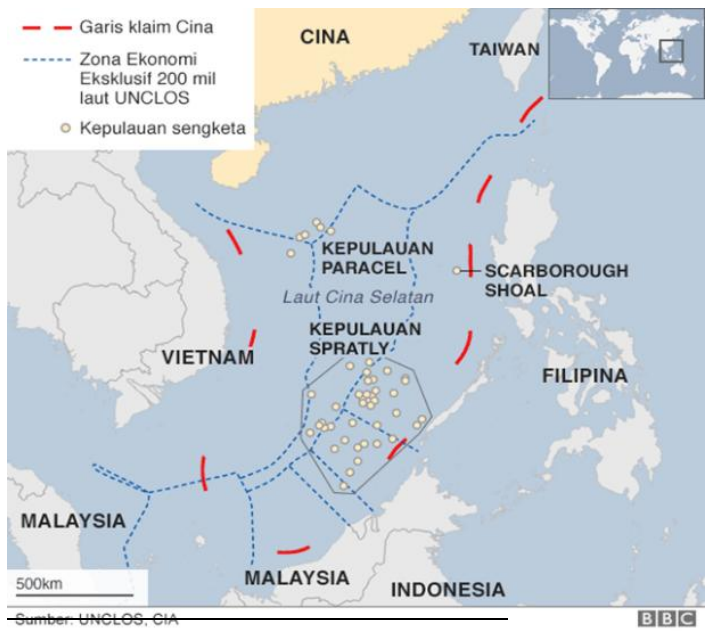

${ }^{6}$ Mikael Weissmann, "The South China Sea: Still No War on the Horizon," Asian Survey 55, no. 3 (2015): 596-617.

${ }^{7}$ Ralph Jennings, "Four Countries Plan Resistance to China in a Disputed Asian Sea," VoA News, 5 Februari 2018, https://www.voanews.com/a/countriespush-for-joint-naval-exercises-in-south-chinasea/4239171.html (diakses pada 7 Desember 2018).
Konflik di LTS terus terjadi. Pada tahun 2007, misalnya, konflik memanas ketika Tiongkok memberikan kewenangan kepada Sansha, kota di Hainan, untuk memerintah Kepulauan Paracel dan Spratly. ${ }^{8}$ Tindakan ini dibarengi dengan meningkatnya patroli angkatan laut Tiongkok yang kemudian menuai protes, terutama dari Vietnam dan Filipina. Penguatan ekonomi dan militer Tiongkok membuat Beijing makin berani beraktivitas di wilayah LTS hingga menangkap kapal nelayan Vietnam yang dianggap melanggar batas wilayah dan bahkan berani mengusir kapal milik angkatan laut AS. Hadirnya AS (serta rencana negara besar lain, seperti Rusia, untuk melakukan patroli militer) di LTS meningkatkan kompleksitas sengketa LTS dan membuatnya menjadi titik konflik global. Dinamika sengketa atas klaim di LTS berpotensi mengancam keamanan regional menjadi titik konflik global, sebab banyak negara-negara besar luar kawasan yang akan terlibat di sana. ${ }^{9}$ Jika negara besar seperti AS saja tidak mampu mempengaruhi sikap Tiongkok yang kadang agresif dalam konflik LTS, apa yang bisa diharapkan dari ASEAN?

Tulisan ini tidak memiliki pretensi untuk menyangkal anggapan-anggapan negatif tersebut. Dalam artikel ini, penulis lebih berusaha untuk melakukan penelitian mengenai apa saja upaya-upaya ASEAN dalam menangani penyelesaian sengketa LTS. Upaya-upaya yang ada meliputi pertemuan-pertemuan formal maupun

\footnotetext{
${ }^{8}$ Mikael Weissman, "Why is there a relative peace in the South China Sea?" dalam Entering Uncharterd Waters? ASEAN and The South China Sea Dispute, Pavin Chachavalpongpun, ed. (Singapore: Institute of Southeast Asian Studies, 2014), 38.

9 Aleja Martinez-Barcelon, "The ASEAN way in the South China Sea disputes" (Hawai: Pacific Forum CSIS, 2016), https://www.csis.org/analysis/pacnet57a-asean-way-south-china-sea-disputes. (diakses pada 7 Desember 2018)
} 
informal, baik dalam konteks regional Asia Tenggara maupun keterlibatan negara luar kawasan Asia Tenggara yang lebih luas. Selanjutnya, penulis mencoba mengamati bagaimana ASEAN Way yang selama ini eksis di ASEAN memengaruhi upaya ASEAN dalam penyelesaian sengketa. Pokok masalah yang ditekankan sebagai diskusi utama adalah mengapa ASEAN Way cenderung dilihat sebagai kegagalan dalam penyelesaian sengketa, dan bagaimana perdebatan tentang apakah ASEAN Way merupakan bagian dari solusi atau masalah terus berlangsung.

Penulis berargumen bahwa ASEAN merupakan organisasi kawasan yang aktif dalam penyelesaian sengketa LTS. Dalam prosesnya, norma-norma ASEAN diduga menjadi kendala bagi kesatuan ASEAN dalam merespon dinamika kawasan, termasuk dalam isu sengketa LTS. Meski telah melakukan berbagai upaya, kesatuan ASEAN dalam menghadapi Tiongkok masih menjadi hambatan. Sampai saat ini, ASEAN dan Tiongkok belum menyepakati kode tata perilaku yang legal dan mengikat. Tiongkok juga berhasil memengaruhi beberapa negara ASEAN untuk tidak membahas isu LTS dalam pertemuan regional. Lebih jauh, isu LTS ini dikhawatirkan memicu campur tangan aktor luar kawasan di dalam negerinya. Secara bersamaan, ASEAN Way membawa keberhasilan bagi ASEAN dalam tiga hal. Pertama, membangun tata regional dalam menghadapi dinamika regional baru. Kedua, tidak adanya konflik saling ancam antarnegara ASEAN. Ketiga, ASEAN berhasil meredam kemunculan perang terbuka di lautan.

Beberapa penelitian telah mengkaji mengenai penggunaan ASEAN Way dalam konflik-konflik Asia Tenggara. Secara umum, Pek Koon Heng melihat bahwa ASEAN Way akan terus menjadi instrumen kunci dalam hubungan internasional di kawasan. ${ }^{10}$ Negara-negara besar seperti AS, Tiongkok, dan Jepang, tidak memiliki mekanisme keamanan multilateral alternatif yang lebih baik. Dengan menggunakan studi kasus, Gillian Goh mengkaji penggunaan ASEAN Way yang memperlihatkan hasil positif dalam penyelesain konflik internal di Kamboja antara pemerintah dan Khmer Merah. ${ }^{11}$ Sementara itu, Dio Herdiawan Tobing mengamati bahwa penggunaan ASEAN Way, terutama prinsip nonintervensi, membuat tindakan negara-negara Asia Tenggara dalam menangani masalah Rohingya menjadi sangat terbatas. ${ }^{12}$ Dua pandangan tersebut mewakili analisis dan interpretasi yang berbeda dari para akademisi hubungan internasional mengenai peran ASEAN Way di kawasan. Tulisan ini bertujuan untuk menjelaskan peran ASEAN Way dalam penyelesain sengketa LTS yang terus berjalan menuju arah yang positif. Namun, ASEAN masih memiliki pekerjaan berat untuk mendorong persetujuan kode tata berperilaku di LTS ke arah yang lebih mengikat.

\section{Metode Penelitian}

Penelitian ini menggunakan metode riset kualitatif yang menelaah mengenai bagaimana fenomena atau entitas sosial diinterpretasikan, dipahami, dialami, dibuat, atau disusun. Dalam pengumpulan data, metode ini menggunakan teknik

\footnotetext{
${ }^{10}$ Pek Koon Heng, The "ASEAN Way" and Regional Security Cooperation in the South China Sea

(European University Institute (EUI) Working Paper: Robert Schuman Centre for Advanced Studies, 2014).

${ }^{11}$ Gillian Goh, "The 'ASEAN Way' Non-Intervention and ASEAN's Role in Conflict Management,"

Stanford Journal of East Asian Affairs 3, no. 1 (2003): 113-118.

${ }^{12}$ Dio Herdiawan Tobing, "The Limits and Possibilities of the ASEAN Way: The Case of Rohingya as Humanitarian Issue in Southeast Asia," dalam The 1st International Conference on South East Asia Studies, 2016, KnE Social Sciences, 148-174.
} 
pengumpulan data yang sangat kontekstual terhadap kasus yang diteliti. Oleh sebab itu, metode kualitatif adalah metode riset yang sangat fleksibel baik dalam pengumpulan maupun pengolahan data. Secara spesifik, dalam ilmu hubungan internasional, metode kualitatif bertujuan menemukan makna dibalik suatu tindakan atau kejadian yang terjadi di arena politik internasional. Dalam artikel ini, penulis berusaha mengurai caracara ASEAN dalam penyelesaian sengketa. Untuk mencapai tujuan tersebut, metode kualitatif mengedepankan metode analisis yang berfokus pada kompleksitas suatu kejadian/ tindakan, detail-detailnya, serta konteks yang mendasari kejadian/ tindakan tersebut. Metode ini memberikan pemahaman yang menyeluruh dan kontekstual atas suatu kejadian/ tindakan menggunakan data yang selengkap mungkin, spesifik, dan sangat memperhatikan detail terkecil (nuanced).

Penulis menggunakan konstruktivisme untuk mempertajam pisau analisis. Konstruktivisme dapat dipahami melalui tiga karakter utama. ${ }^{13}$ Pertama, konstruktivisme menekankan bahwa struktur normatif sama pentingnya dengan struktur material. Konstruktivisme berargumen bahwa ide, kepercayaan, dan nilai harus dilihat sebagai bagian dari struktur sebab hal-hal tersebut memiliki pengaruh yang kuat dalam tindakan politik suatu aktor. Kedua, konstruktivisme menekankan pentingnya melihat bagaimana struktur non-material (ide, kepercayaan, dan nilai) mempengaruhi identitas yang terbentuk sebab identitas menentukan kepentingan dan kepentingan menentukan tindakan. Ketiga, konstruktivisme menekankan bahwa agen dan struktur memiliki hubungan saling mempengaruhi yang sama kuat. Struktur memang

${ }^{13}$ Christian Reus-Smit, "Constructivism," dalam Theories of International Relations, ed. S. Burchill, et al. (New York: Palgrave Macmillan, 2005), 188-212. mempengaruhi bagaimana agen bertindak, namun struktur itu sendiri terbentuk dari tindakan-tindakan yang dilakukan oleh agen. Oleh sebab itu, dari kacamata konstruktivisme, struktur non-material mempengaruhi tidak hanya apa yang dianggap bisa dilakukan namun juga apa yang dianggap perlu dilakukan oleh suatu aktor. Dengan bahasa yang lebih sederhana, struktur non-material tidak hanya mempengaruhi strategi yang dipilih oleh suatu aktor, namun juga mempengaruhi tujuan atau kepentingan yang dimiliki oleh aktor tersebut dan juga dipengaruhi oleh tindakan yang dilakukan oleh aktor tersebut.

Dalam studi organisasi internasional, konstruktivisme meminta penggunanya untuk tidak hanya melihat ontologi material yang ada di suatu organisasi internasional, seperti kepentingan, peraturan tertulis, traktat, atau perjanjian. Konstruktivisme melihat tindakan suatu negara sebagai sebuah konstruksi sosial yang dipengaruhi oleh struktur non-material, baik pada level domestik maupun internasional. Oleh sebab itu, dalam menjelaskan tindakan suatu negara, konstruktivisme akan melihat identitas yang mendasari tindakan tersebut serta bagaimana identitas itu sendiri dibentuk oleh ide, kepercayaan dan nilai yang tertanam (embedded) di kawasan maupun pada level domestik.

Dalam konteks ASEAN, ASEAN Way perlu dilihat sebagai sebuah sistem struktur non-material. Melihat ASEAN Way sedemikian rupa akan menjelaskan bagaimana ASEAN Way punya kapabilitas untuk mempengaruhi bagaimana negara bertindak bahkan ketika tidak memiliki kekuatan legal yang kuat. Melihat ASEAN Way sebagai struktur non-material berarti juga memahami bahwa ASEAN Way harus dilihat tidak sekedar sebagai "aturan" yang mendikte apa yang boleh dan tidak boleh dilakukan (dan dalam konteks ini ASEAN 
Way sering dianggap lemah), melainkan sebagai ide, kepercayaan, dan nilai yang mempengaruhi apa yang dianggap negaranegara anggota sebagai hal yang perlu dilakukan. Melihat ASEAN Way dengan cara seperti ini tidak hanya akan menjelaskan bagaimana ASEAN Way memiliki peran signifikan dalam sengketa LTS namun juga akan memberikan gambaran mengenai kekurangan-kekurangan ASEAN Way. Konstruktivis memberikan perspektif alternatif dengan berusaha menunjukkan peran norma di kawasan Asia Tenggara daripada agenda politik luar negeri seperti perang antarnegara dan pembentukan aliansi dengan negara luar kawasan yang kerap ditulis oleh para realis (Busse, 1999: 39). ${ }^{14}$ Dalam lingkup konstruktivis tersebut, tulisan ini berusaha menganalisis peran norma ASEAN dalam penyelesaian sengketa LTS.

Menurut Yukawa, ASEAN Way merupakan "a set of rules of the ASEAN centered on the principle of non-interference and consensus decision-making". ${ }^{15}$ Pernyataan itu sejalan dengan Katsumata yang melihat ASEAN Way sebagai "a set of diplomatic norms shared by the member [states]". ${ }^{16}$ Sementara itu, Iwao Fujisawa menggarisbawahi ASEAN Way sebagai proses pengambilan keputusan yang lebih mengutamakan konsultasi dan konsensus di antara para anggotanya. ${ }^{17}$ Dengan ASEAN Way, negara-negara anggota memilih interaksi dan kerja sama regional yang berdasar atas informalitas, proses konsensus, dan tawar-menawar dengan cara nonkonfrontasi ketimbang cara-cara

\footnotetext{
${ }^{14}$ Busse, "Constructivism," 39.

15 Taku Yukawa, "The ASEAN Way as a symbol: an analysis of discourses on the ASEAN Norms," The Pacific Review 31, no. 3 (2018): 298.

${ }^{16}$ Hiro Katsumata, "Reconstruction of Diplomatic Norms in Southeast Asia: The Case for Strict Adherence to the ASEAN Way," Contemporary Southeast Asia 25, no. 1 (2003): 104.

${ }^{17}$ Fujisawa, "The Use and Abuse," 2.
}

permusuhan, pengambilan suara mayoritas, atau proses pengadilan. Selain itu, ASEAN juga memegang prinsip dan norma seperti menentang penggunaan kekerasan dan lebih mengutamakan solusi damai dalam menghadapi persoalan, otonomi regional atau tidak menggantungkan diri kepada negara besar luar kawasan, serta prinsip nonintervensi, yang berarti bahwa antarnegara ASEAN tidak diperbolehkan mencampuri urusan domestik negara lain. ${ }^{18}$

\section{Hasil dan Pembahasan}

\section{Akomodasi ASEAN dalam Upaya Penyelesaian Sengketa}

Pada bagian ini, penulis membahas cara-cara yang ditempuh oleh negara-negara ASEAN dalam menyelesaikan sengketa LTS. Dengan adanya Singapura, Indonesia, Jepang, Amerika Serikat, dan Rusia yang memiliki kepentingan cukup besar, selain enam negara pengklaim utama, dialog di tingkat regional untuk pengembangan pembicaraan sengketa LTS agaknya tidak bisa dihindarkan. Tensi atau dinamika konflik yang bisa sewaktu-waktu memanas harus coba diselesaikan dengan cara-cara yang damai. Tentu saja ASEAN harus mengambil peran dalam masalah ini. Penulis memaparkan bagaimana ASEAN mengakomodasi dialog-dialog di tengah dinamika konflik LTS. ASEAN sebagai organisasi regional di kawasan Asia Tenggara tentu tidak tinggal diam. Setidaknya ada beberapa kepentingan bagi ASEAN dalam menyelesaikan sengketa LCS. $^{19}$ Pertama, ASEAN memiliki

\footnotetext{
${ }^{18}$ Agus Haryanto dan Isman Pasha, Diplomasi Indonesia: Realitas dan Prospek (Yogyakarta: Pustaka Ilmu, 2016), 208-214.

${ }^{19}$ Claudia Conchita Renyoet, "Diplomasi Informal sebagai Pendekatan dalam Proses Penyelesaian Konflik Laut Cina Selatan" (Tesis. Yogyakarta: Universitas Gadjah, 2012), 61.
} 
kepentingan untuk menjaga stabilitas hubungan negara-negara anggota. Kedua, wilayah yang sangat strategis seperti LTS membuat ASEAN harus selalu waspada mengenai berbagai potensi konflik di kawasan, karena dikhawatirkan memengaruhi perkembangan ekonomi kawasan. Ketiga, masalah LTS menjadi pembuktian apakah ASEAN merupakan organisasi regional yang solid atau tidak.

Upaya-upaya ASEAN dan negaranegara Asia Tenggara untuk menyelesaikan masalah keamanan, terutama yang berkaitan dengan LTS, adalah sebagai berikut:

Pertama, melalui deklarasi-deklarasi keamanan. Pada tahun 1971, negara-negara ASEAN menandatangani sebuah deklarasi mengenai kawasan damai, bebas, dan netral (Zone of Peace, Freedom, and Neutrality) atau ZOPFAN di Kuala Lumpur. Deklarasi ini merupakan komitmen politik dan kerjasama politik dan keamanan ASEAN untuk pertama kalinya dalam sejarah ASEAN. Konsep ZOPFAN inilah yang mengatur hubungan antarnegara di Asia Tenggara maupun antara negara-negara ASEAN dengan negara lain di luar kawasan. Titik penekanan ZOPFAN ada pada "kesepakatan untuk menerima berbagai langkah dan sikap untuk saling menahan diri" ${ }^{20}$ Selanjutnya, pada tahun 1976, ASEAN menandatangani dokumen Declaration of ASEAN Concord atau yang sering disebut dengan Bali Concord I dan Perjanjian Persahabatan dan Kerjasama atau Treaty of Amity and Cooperation (TAC). Dalam Bali Concord I dan TAC inilah tercantum komitmen dan penyelesaian secara

\footnotetext{
${ }^{20}$ Hasjim Djalal, et al., Usaha-Usaha Mengalihkan Potensi Konflik di Laut Cina Selatan Menjadi Potensi Kerjasama, Proyek Penelitian dan Pengembangan Politik Luar Negeri Yayasan Pusat Studi Asia Tenggara dengan Badan Penelitian dan Pengembangan Departemen Luar Negeri Republik Indonesia (Jakarta: Yayasan Pusat Studi Asia Tenggara, 1995), 25.
}

damai antarnegara ASEAN dengan cara-cara Asia Tenggara (yang kemudian sering disebut "ASEAN Way") tanpa campur tangan pihak luar, yaitu pada ayat $13-17 .{ }^{21}$ Meskipun TAC masih memiliki sifat longgar, di mana pihak yang bersengketa tidak terlalu terikat untuk menerima adanya mediasi, TAC merupakan langkah maju dalam realisasi ZOPFAN. Dua deklarasi keamanan di atas merupakan dua dasar atau prinsip yang akan selalu dipakai ASEAN, terutama dalam menyelesaikan masalah keamanan seperti LTS. Dalam dokumen TAC, misalnya, kemudian dirumuskan enam prinsip yang harus dihormati para penandatangan Bali Concord I. Prinsipprinsip tersebut ada dalam pasal 2 TAC: (1) saling menghormati kemerdekaan, kedaulatan, persamaan derajat, integritas teritorial, dan identitas nasional semua bangsa; (2) hak masing-masing negara untuk hidup bebas dari campur tangan, subversi, atau paksaan; (3) tidak mencampuri urusan dalam negeri negara lain; (4) penyelesaian sengketa dengan cara-cara damai; (5) berjanji untuk tidak melakukan ancaman atau menggunakan kekerasan; serta (6) mengadakan kerjasama efektif di kalangan ASEAN. ${ }^{22}$

Pada tahun 2002, ASEAN dan Tiongkok berhasil menandatangani Declaration on the Conduct of Parties in South China Sea yang merupakan deklarasi Tata Berperilaku di sekitar kawasan LCS. Pada tahun 2005, dalam rangka melaksanakan pengimplementasian dari Declaration on the Conduct of Parties in South China Sea (DOC), ASEAN-Tiongkok melakukan Joint Working Group dan menghasilkan kesepakatan bahwa kedua belah pihak, baik ASEAN maupun

\footnotetext{
${ }^{21}$ ASEAN, Handbook of Selected ASEAN Political Documents (Jakarta: ASEAN Secretariat, 2003), 2527.

${ }^{22}$ ASEAN, Handbook of Selected ASEAN, 22.
} 
Tiongkok, akan berkomitmen menjaga perdamaian dan stabilitas di kawasan LTS. Beberapa kelanjutan pertemuan dari kelompok kerja gabungan tersebut terus dilakukan. Pada 16-17 April 2010, misalnya, dilakukan ASEAN-China Joint Working Group Meeting on the Implementation of the DoC yang diselenggarakan di Hanoi, Vietnam. Pertemuan ini menyepakati bahwa (1) DOC tetap dan akan selalu menjadi salah satu dokumen yang signifikan bagi ASEAN dan Tiongkok, (2) implementasi dari DOC penting bagi perdamaian dan stabilitas baik di wilayah LTS maupun ASEAN, (3) kendati DOC dan Draft Guidelines akan melalui observasi lebih, para pihak harus terus menghormati setiap aspek yang terkandung pada DOC. Pada tanggal 21-22 Desember 2010, kembali diadakan ASEAN-China Joint Working Group Meeting on the Implementation of the DOC di Kunming. Dalam pertemuan tersebut, Tiongkok menyampaikan adanya perbedaan pemahaman terhadap DoC dan draft Guidelines di antara Tiongkok dan beberapa anggota ASEAN. Pada tanggal 17-19 April 2011, kembali diadakan pertemuan ke-6 ASEAN-China Joint Working Group on the Implementation of the Declaration on the Conduct of Parties in the South China Sea (DOC) yang diselenggarakan di Medan dan diketuai oleh Vietnam dan Tiongkok. ${ }^{23}$

Kedua, melalui KTT ASEAN dan pertemuan menteri luar negeri. Masalah sengketa LTS beberapa kali dilakukan dalam KTT ASEAN. Pada tahun 1995, KTT ASEAN $\mathrm{V}$ menghasilkan traktat mengenai kawasan bebas senjata nuklir di Asia Tenggara (Treaty on South East Asia ZoneNuclear Free Zone). Hal ini sangat penting untuk mencegah perang yang lebih buruk di masa depan. Pada November 2007, dalam

\footnotetext{
${ }^{23}$ Deplu RI, Hubungan Kemitraan ASEAN-China (Jakarta: Departemen Luar Negeri Republik Indonesia, 2011), 22.
}

KTT ASEAN ke-11 di Singapura, Tiongkok menandatangani beberapa kesepakatan dengan ASEAN di bidang politik dan keamanan, antara lain "MoU between the Government of the Member Countries of the Association of Southest Asian Nations (ASEAN) and the Government of the people's Republic of China on Cooperation in the field of non-traditional security issues dan the declaration on the Condust of Parties in the South China Sea (DoC)" sebagai confidence-building measures antara pihak-pihak yang berkepentingan terhadap penyelesaian ketegangan di LTS. $^{24}$

Pada pertemuan KTT ASEAN ke-17 yang diselenggarakan pada 30 Oktober 2010 di Hanoi, Vietnam, kembali membahas masalah DOC. Dalam pertemuan itu disepakati langkah-langkah terkait implementasi DOC, diantaranya sebagai berikut: (1) masalah teritorial harus diselesaikan oleh negara-negara yang bersangkutan dengan cara damai berdasarkan hukum internasional dan UNCLOS 1982; (2) pentingnya tercipta keamanan dan prinsip kebebasan navigasi di LTS mengingat kawasan tersebut merupakan jalur pelayaran penting atau Sea Lane of Communication (SLOC); (3) memanfaatkan mekanisme regional dalam membangun saling percaya dalam isu tersebut dengan pengimplementasi dari DOC serta mengupayakan tersusunnya Code of Conduct in the South China Sea (COC) (ASEAN, 2012c). ${ }^{25}$

Pada KTT ASEAN ke-19 di Bali pada 17-19 November 2011, menghasilkan Bali Concord III dimana terdapat 9 kesepakatan

\footnotetext{
${ }^{24}$ ASEAN, Chairman's Statement of the 11th ASEANChina Summit Singapore, 20 November 2007, http://asean.org/?static_post=chairman-s-statementof-the-11th-asean-china-summit-singapore-20november-2007 (diakses pada 4 Desember 2018).

${ }^{25}$ ASEAN, Chairman's Statement of the 17th ASEAN Summit, http://asean.org/?static_post=chairman-sstatement-of-the-17th-asean-summit (diakses pada 4 Desember 2018).
} 
di bidang politik dan keamanan, bidang ekonomi, dan bidang sosial budaya. Di bidang politik dan keamanan, Bali Concord III memberi fokus, diantaranya, pada penyelesaian konflik kawasan. ${ }^{26}$ Sebagai tindak lanjut atas disepakatinya guidelines dari DOC, pembahasan isu LTS di ASEAN telah mengarah pada upaya identifikasi proyek-proyek kerja sama ASEANTiongkok di kawasan tersebut. KTT ASEAN ke-22 di Bandar Seri Begawan, Brunei, pada 24 April 2013 juga kembali membicarakan masalah LTS. Dalam pertemuan tersebut, negara-negara ASEAN berusaha mengajak Tiongkok untuk menyetujui code of conduct (COC) atau tata berperilaku dalam penyelesaian masalah di LTS. ${ }^{27}$

Tidak hanya dalam KTT ASEAN, isu LTS turut dibahas dalam Pertemuan Menteri Luar Negeri ASEAN. Pada tahun 1992, Pertemuan Menteri Luar Negeri ASEAN di Manila menghasilkan ASEAN Declaration on the South China Sea yang menegaskan "necessity to resolve all sovereignty and jurisdictional issues pertaining to the South China Sea by peaceful means, without resort to force", dan keinginan "all parties concerned to exercise restraint". ${ }^{28}$ Pertemuan Menteri Luar Negeri ASEAN (AMM Retret) pada 16-17 Januari 2011 membahas isu-isu kawasan dan internasional yang menjadi perhatian bersama ASEAN. Dalam pembahasan isu LTS, pertemuan berpandangan bahwa perlu adanya percepatan dalam proses finalisasi guidelines karena negosiasi sudah berjalan selama

\footnotetext{
${ }^{26}$ ASEAN, Bali Declaration on ASEAN Community in a Global Community of Nations "Bali Concord III" (Jakarta: ASEAN Secretariat, 2011).

27 ASEAN, Chairman's Statement of the 16th ASEANChina Summit (Bandar Seri Begawan: Brunei Darussalam, 2013).

${ }^{28}$ Amitav Acharya, Constructing a Security Community in Southeast Asia: ASEAN and The Problem of Regional Order, 2nd ed (New York: Routledge, 2009), 134.
}

sembilan tahun tanpa hasil. Pertemuan tersebut juga membahas mengenai implementasian DOC oleh ASEAN dan Tiongkok secara bersama-sama agar dapat menciptakan stabilitas di kawasan LTS. Pada bulan Juli 2011, Pertemuan Tingkat Menteri Luar Negeri ASEAN+3, dilakukannya penandatanganan penegasan komitmen tentang DOC oleh semua negara yang bersengketa. Penegasan tersebut terdiri dari delapan poin, diantaranya semua pihak yang berseteru dalam masalah LTS harus tetap melanjutkan dialog agar terhindar dari konflik terbuka. Selain itu, setiap keputusan yang diambil untuk mengatasi konflik tersebut, harus melalui konsensus dan dilaporkan setiap tahun pada pertemuan tingkat menteri ASEAN-Tiongkok. ${ }^{29}$ Pada bulan Agustus 2018, para menteri luar negeri negara ASEAN dan Tiongkok menyetujui draf tunggal teks negosiasi tata berperilaku di LTS. Untuk menjadi tata berperilaku yang lebih mengikat, draf tunggal ini merupakan kemajuan yang sangat berarti bagi ASEAN dan Tiongkok.

Ketiga, melalui ASEAN Regional Forum $(A R F)$. ARF dibentuk pada tahun 1994. Forum ini dibentuk setelah disepakati oleh para pemerintah negara-negara ASEAN dalam Pertemuan Menteri ASEAN yang diselenggarakan pada 23-25 Juli 1993. Pertemuan ARF pertama kali dilangsungkan di Bangkok pada 25 Juli $1994 .^{30}$ Masalah LCS tepat dibahas dalam ARF karena hal ini sesuai dengan tujuan ARF dibentuk, yaitu "to foster constructive dialogue and consultation on political and security issues of common interest and concern" dan "to make significant contributions to efforts towards confidence-building and preventive

\footnotetext{
${ }^{29}$ ASEAN, ASEAN Plus Three Documents Series 2011-2015 (Jakarta: The ASEAN Secretariat, 2016).

${ }^{30}$ Kemlu RI, "ASEAN: Selayang Pandang," https://www.kemlu.go.id/Documents/ASEAN/ASP_2 012_Edisi_20.pdf (diakses pada 4 Desember 2018).
} 
diplomacy in the Asia-Pacific region". 31 Proses kerjasama dalam ARF terbagi atas 3 tahap yaitu tahap Confidence Building Measures (CBMs), Preventive Diplomacy (PD) dan Conflict Resolution (CR). Mengapa pembicaraan dalam ARF menjadi penting? Sebab isu LTS melibatkan banyak pihak, terutama yang berkaitan dengan kebebasan navigasi di wilayah tersebut. Pihak-pihak yang tidak terlibat klaim langsung pun berkepentingan dalam mencari penjelasan dan perkembangan mengenai isu LTS.

Dalam perkembangan ARF kemudian, hadir berbagai negara besar seperti Amerika Serikat, Rusia, dan India, yang dilandasi berbagai kepentingan. AS, misalnya, menyatakan bahwa mereka ingin IndoPacific sebagai kawasan yang terbuka dengan meliputi "peaceful resolution of territorial and maritime disputes". ${ }^{32}$ Hanya saja, Tiongkok enggan membicarakan masalah LTS ini lebih jauh dalam perundingan multilateral seperti ARF. Pada pertemuan ARF di Brunei tahun 1995, juru bicara Menteri Luar Negeri Tiongkok mengatakan bahwa Tiongkok "menolak peran ARF dalam mendiskusikan masalah ini". ${ }^{33}$ Karena terlalu banyak kekuatan besar luar kawasan yang terlibat di dalamnya, Hasjim Djalal mengamati bahwa upaya ARF dalam isu LTS cenderung berjalan tidak terlalu efektif. ${ }^{34}$ Meski demikian, isu LTS terus masuk dalam ARF, Pembicaraan penting dalam ARF mengenai LTS diantaranya ada pada ARF ke-18 di Bali pada Juli 2011. Pertemuan itu menghasilkan

\footnotetext{
${ }^{31}$ ASEAN, "About The ASEAN Regional Forum," aseanregionalforum.asean.org/about.html (diakses pada 4 Desember 2018).

${ }^{32}$ Michael R. Pompeo, Remarks on "America's IndoPacific Economic Vision" (Washington, D.C.: US Department of State, 2018).

33 Acharya, "Constructing a Security Community."

${ }^{34}$ Hasjim Djalal, "Managing Potential Conflicts in the South China Sea: Lessons Learned," dalam Maritime Regime Building, Mark J Valencia (Ed.) (Britain: Kluwer Law International, 2001), 88.
}

beberapa kesepakatan antara ASEAN dan Tiongkok mengenai komitmen dalam pelaksanaan DOC para pihak di LTS. ${ }^{35}$

Keempat, melalui pertemuan informal Managing Potential Conflicts in the South China Sea (MPCSCS). MPCSCS merupakan pertemuan informal yang digagas oleh Indonesia dan didanai oleh Kanada pada tahun 1989. Pertemuan ini bertujuan "to promote peace, stability, and cooperation in the South China Sea". Jadi, ada dua target utama, yaitu belajar bagaimana cara bekerja sama dan bagaimana mengimplementasikan kerja sama itu. ${ }^{36}$ Pertemuan pertama MPCSCS tahun 1990 hanya dihadiri oleh enam negara ASEAN. MPCSCS kemudian berlangsung tiap tahun dan dihadiri oleh seluruh anggota ASEAN, ditambah Tiongkok dan Taiwan. Materi yang terus berjalan dengan baik adalah pembicaraan mengenai penelitian kelautan, seperti ekspedisi biodiversitas (tahun 2002), pelatihan sains dan teknologi kelautan di LTS (2009), serta kerja sama menghadapi perubahan iklim global (2011). Meski demikian, diskusi mengenai isu teritorial dan kedaulatan dalam politik dan keamanan masih tersendat karena beberapa pihak menolak untuk membicarakan hal tersebut. Namun, diskusi dalam MPCSCS diharapkan membawa saling pengertian di antara para negara-negara untuk menjaga kawasan LTS agar tetap damai dan stabil. Seiring berjalannya waktu, pusat-pusat penelitian dan kelompok-kelompok akademisi dari berbagai negara semakin terlibat dalam inisiatif informal ini, seperti akademisi

\footnotetext{
${ }^{35}$ Ernest Bower, "18th ASEAN Regional Forum in Bali, Indonesia," Center for Strategic \& International Studies, 1 Agustus 2011, https://www.csis.org/analysis/18th-asean-regionalforum-bali-indonesia (diakses 4 Desember 2018). ${ }^{36}$ Djalal, "Managing Potential Conflicts," 89-90.
} 
Tiongkok, Vietnam, Malaysia, Singapura, Taiwan, dan lain sebagainya. ${ }^{37}$

\section{Penggunaan ASEAN Way}

ASEAN memiliki seperangkat aturan main dalam hubungan antarnegara di kawasan Asia Tenggara yang sering disebut dengan ASEAN Way. ASEAN Way merupakan norma-norma yang melekat pada institusi dengan menekankan prinsip nonintervensi yang menghormati kedaulatan negara lain serta menggunakan pendekatan konsultasi dan konsensus dalam interaksi penyelesaian isu di kawasan daripada penggunaan cara-cara konfrontasi/ kekerasan. Walter Woon menyatakan bahwa ada tiga aspek penting dalam ASEAN Way. ${ }^{38}$ Pertama, hasrat untuk tidak kehilangan muka atau membuat negara lain kehilangan muka. Kedua, memilih konsensus daripada konfrontasi. Ketiga, penolakan terhadap gagasan bahwa suatu negara memiliki hak untuk mencampuri urusan internal negara lain. Sementara menurut Acharya, tata perilaku ASEAN Way ditunjukkan dengan cara: (1) kepatuhan terhadap cara-cara nonintervensi, non-kekerasan, dan resolusi perdamaian dalam konflik; (2) mempromosikan otonomi regional dan kolektivitas; (3) penolakan pakta militer multilateral; dan (4) preferensi pada norma sosio-kultural yang berdasarkan konsultasi informal dan konsensus daripada norma legal-rasional dalam pembuatan keputusan. ${ }^{39}$ Dengan demikian, penulis menggarisbawahi ASEAN Way sebagai kecenderungan ASEAN dan negara-negara Asia Tenggara untuk

\footnotetext{
${ }^{37}$ Hasjim Djalal, "South China Sea: Contribution of 2nd Track Diplomacy/Workshop Process to Progressive Development of Regional Peace and Cooperation," dipresentasikan di Manila, Filipina, 1617 Oktober 2011.

${ }^{38}$ Walter Woon, Dispute Settlement the ASEAN Way (Singapore: Center for International Law, 2012), 1.

${ }^{39}$ Acharya, Constructing a Security Community, 4872.
}

melakukan proses interaksi dan kerja sama yang berdasar atas non-intervensi, informalitas, pembuatan keputusan secara konsensus, dan perilaku non-konfrontasi. Dalam isu LTS, proses pembuatan keputusan dengan cara-cara ASEAN (ASEAN Way) membantu negara-negara Asia Tenggara dan kawasan sekitarnya untuk saling menghormati satu sama lain dan menghasilkan perdamaian di kawasan.

Pembicaraan mengenai norma ASEAN tidak lepas dari sejarah awal pembentukan ASEAN sekitar pertengahan 1960-an yang membutuhkan standar untuk menghormati kedaulatan masing-masing negara. Prinsip ASEAN mengenai non-intervensi memiliki konteks eksternal dan internal. ${ }^{40}$ Konteks eksternal waktu itu merujuk pada kekuatan luar kawasan, terutama AS dan Rusia. Negara-negara mula anggota ASEAN kecuali Thailand merupakan negara berkembang yang baru merdeka pascaPerang Dunia II dan tidak ingin kolonialisasi Barat hadir kembali di Asia Tenggara. Oleh karena itu, intervensi dari negara besar masih menjadi perhatian penting negara para pendiri ASEAN, baik intervensi dalam politik domestik maupun integritas teritorial. Secara bersamaan, konteks internal merujuk pada sikap saling respek terhadap kedaulatan terhadap masing-masing anggota ASEAN. Dengan demikian, negara-negara anggota ASEAN yang baru merdeka ini bisa fokus dalam pembangunan ekonomi domestik.

Kemunculan prinsip tersebut kemudian dinyatakan dalam dua dokumen ASEAN yang paling dasar dan penting, yaitu Bali Concord I dan TAC yang ditandatangani di hari yang sama pada tahun 1976. Dalam dokumen-dokumen tersebut negara-negara ASEAN menyatakan untuk selalu mengandalkan proses penyelesaian secara damai di antara perbedaan-perbedaan internal kawasan, mempromosikan kerja

${ }^{40}$ Yukawa, "The ASEAN Way," 2. 
sama damai, serta mengembangkan kesadaran dan penghormatan terhadap sesama sesuai prinsip persamaan kedaulatan dan non-intervensi. Para pemimpin negaranegara anggota ASEAN sendiri mencatat bahwa ASEAN Way merupakan norma yang telah menjadi dasar pijakan di Asia Tenggara. Wakil Perdana Menteri Malaysia Datuk Musa Hitam menyatakan:

"Because of ASEAN, we have been able to establish the fundamental ground rules for the game of peace and amity between us all. What are these fundamental ground rules? First, the principle of strict non-interference in each other's internal affairs. Second, the principle of pacific settlement of disputes. Third, respect for each other's independence. Fourth, strict respect for the territorial integrity of each of the ASEAN states.... The ASEAN states have declared these ground rules...we have enacted them, we have imbibed them, and most important, we have acted and lived by them" (Pidato Datuk Musa Hitam di Honolulu, 29 Oktober 1985). ${ }^{41}$

Dengan melakukan analisis terhadap akomodasi ASEAN dan negara-negara Asia Tenggara di atas, penulis mengamati beberapa indikasi penerapan ASEAN Way dalam menghadapi masalah LTS. Pertama, ASEAN dan beberapa negara Asia Tenggara mengadakan pertemuan-pertemuan sebagai sarana mutual understanding. Sejak awal, ASEAN secara eksplisit menolak pembentukan pakta militer dan lebih fokus pada dialog, konsultasi, dan pertemuan informal. Perkembangan ASEAN tidak mengarah pada kerja sama keamanan kolektif seperti North Atlantic Treaty Organization (NATO, 1949-sekarang)

\footnotetext{
${ }^{41}$ Dikutip dalam Acharya, Constructing a Security Community, 71.
}

maupun Southeast Asia Treaty Organization (SEATO, 1954-1977). ASEAN juga tidak mencoba meniru model integrasi Uni Eropa. Para pemimpin ASEAN lebih cenderung membentuk organisasi regional berbasis norma yang bersandar pada "the route of informality, of eschewing legal formulations and legally binding commitments, of avoiding elaborate regional, supranational institutions". ${ }^{2}$ Hal inilah yang ditunjukkan dalam penyelesaian masalah di LTS. ASEAN Declaration on the South China Sea tahun 1992 menyatakan bahwa penyelesaian isu ini harus mengacu kepada prinsip-prinsip dalam TAC tahun 1976, terutama yang tercantum dalam pasal 2. Cara ASEAN melalui pertemuan informal terlihat dalam MPCSCS yang diinisiasi oleh Indonesia. Di sini, negara-negara pengklaim hadir dan membicarakan soal isu LTS bersama-sama, meskipun tidak menyinggung isu keamanan dan politik. MPCSCS membuat negaranegara terus terlibat dalam dialog dan menumbuhkan semangat kerja sama di area sengketa. $^{43}$

Kedua, mempererat relasi di antara negara-negara kawasan, baik yang terlibat langsung maupun tidak, melalui berbagai bidang, misalnya ekonomi, sosial, sains, atau kultural. Hal inilah yang tercantum sejak tahun 1976 dalam Bali Concord I ketika lima negara ASEAN secara eksplisit mengingkari tujuan kerja sama keamanan dan menyatakan fokus pada kerja sama ekonomi, sosial, kultural, teknikal, pendidikan, dan saintifik. Hal itu berlanjut dalam ASEAN Declaration on the South China Sea tahun 1992. Deklarasi tersebut menyatakan bahwa menteri-menteri ASEAN sepakat untuk mengeksplorasi

\footnotetext{
${ }^{42}$ Rudolfo Severino, Southeast Asia in Search of an ASEAN Community (Singapore: Institute of Southeast Asian Studies, 2006).

${ }^{43}$ Djalal, "South China Sea."
} 
"the possibility of cooperation in the South China Sea relating to the safety of maritime navigation and communication, protection against pollution of the marine environment, coordination of search and rescue operations, efforts towards combating piracy and armed robbery as well as collaboration in the campaign against illicit trafficking in drugs". 4

Pernyataan itu menegaskan bahwa ASEAN akan lebih fokus hal-hal yang terkait dengan kerja sama maritim di LTS dan penanganan kejahatan transnasional di kawasan. MPCSCS merupakan pertemuan yang menitikberatkan pada kerja sama di luar politik. Kerja sama para ahli berbagai negara dalam MPCSCS yang paling menunjukkan kemajuan adalah bidang penelitian kelautan, seperti ekspedisi bersama biodiversitas di Kepulauan Anambas dan penelitian penanganan naiknya permukaan air laut sebagai dampak perubahan iklim global. Tidak hanya itu, inisiatif informal MPCSCS semakin mempererat dialog antarpihak di antara anggota dan bahkan memperlihatkan ketertarikan lembaga-lembaga riset dan kelompok akademisi dari berbagai negara untuk bekerja sama. ${ }^{45}$

Ketiga, menyelesaikan masalah dengan konsensus. Memaksa negara lain untuk melakukan suatu tindakan merupakan hal yang dihindari dalam pendekatan ASEAN ketika menyelesaikan masalah. Konflik sebisa mungkin ditangani dengan menghormati kedaulatan dan menjunjung tinggi prinsip non-intervensi terhadap negara lain. ${ }^{46}$ Ketika Tiongkok menyatakan tidak setuju jika pembicaraan mengenai LTS membawa aktor luar kawasan dalam ARF,

\footnotetext{
${ }^{44}$ ASEAN, Handbook of Selected ASEAN, 36. Rudolfo Severino, "ASEAN and the South China Sea," Security Challenges 6, no. 2 (2010): 41.

${ }^{45}$ Djalal, "South China Sea."

${ }^{46}$ Kivimäki, "The Long Peace," 68.
}

forum tidak memaksakan diri untuk memasukkan AS dan Jepang sebagai negara yang aktif dalam forum pertemuan. ASEAN juga pernah mencapai kata tidak sepakat ketika pada tahun 2016 Kamboja menolak langkah ASEAN untuk menyatakan kritik terhadap perilaku Tiongkok atas klaimnya di LTS. $^{47}$ Meskipun hanya satu negara yang menolak, ASEAN tetap tidak bisa memasukkan kritik terhadap Tiongkok dalam pernyataan bersama atas dasar pengambilan kebijakan secara konsensus.

Dengan mencermati indikasi-indikasi di atas, ASEAN Way merupakan struktur normatif yang memiliki pengaruh kuat dalam menyelesaikan konflik LTS. Pengaruh non-material dalam ASEAN Way ini kemudian menentukan cara-cara negara ASEAN dan Tiongkok ketika melakukan tindakan-tindakan yang dalam arena hubungan internasional. Di sini agen, yaitu pihak-pihak yang terlibat, dan struktur nonmaterial, yaitu ASEAN Way, memiliki hubungan yang saling mempengaruhi. ASEAN, mengacu dari berbagai dokumen seperti TAC, mempengaruhi proses dialog dan negosiasi yang berjalan, sementara pihak-pihak yang terlibat juga menyandarkan diri pada ASEAN Way untuk memastikan bahwa akomodasi kawasan bisa terus berlanjut.

\section{Catatan-catatan Keberhasilan?}

Dalam melihat akomodasi kawasan terhadap isu LTS, ASEAN Way setidaknya mendorong keberhasilan dalam tiga aspek penting. Pertama, stabilitas kawasan LTS yang relatif damai. Bagaimana pun, dialogdialog yang dibangun oleh ASEAN dan

\footnotetext{
${ }^{47}$ Manuel Mogato, Michael Martina, \& Ben Blanchard, "ASEAN deadlocked on South China Sea Cambodia blocks statement," Reuters, 25 Juli 2016, https://www.reuters.com/article/us-southchinasearuling-asean/asean-deadlocked-on-south-china-seacambodia-blocks-statement-idUSKCN1050F6 (diakses pada 8 Desember 2018).
} 
negara-negara anggotanya ketika berhadapan dengan suatu konflik sangat penting daripada upaya-upaya untuk menghindari konflik. Sebagai organisasi kawasan dengan banyak negara yang terlibat di dalamnya, konflik merupakan hal yang tidak bisa dihindari. Dengan memahami bahwa kesepahaman tidak mungkin selalu dapat terjadi dalam segala hal, cara-cara ASEAN ketika menangani isu LTS agar tidak menjadi perang terbuka merupakan prestasi yang penting untuk dicatat. Konsensus yang dimaksud dalam ASEAN Way bukan berarti kebulatan suara, melainkan komitmen untuk menemukan cara-cara untuk terus maju dengan mempertahankan apa yang secara umum didukung oleh negara-negara anggota. ${ }^{48}$ Di sini, meski tidak semua negara nyaman dengan situasi yang ada, hal itu tidak berpretensi untuk menganggu kepentingan dasar semua pihak. Dari situ seminar informal MPCSCS, misalnya, bisa lebih dipahami sebagai pertemuan dengan fungsi membangun komunikasi damai daripada sebuah solusi masalah. ${ }^{49}$ Dalam ARF, isu LTS tidak mengarah pada penyelesaian multilateral karena permintaan Tiongkok yang menganggap ARF bukan forum yang tepat untuk mendiskusikannya. Begitu juga dengan masalah tata perilaku yang ketat (COC) di LTS tidak kunjung disepakati. ASEAN melihat deklarasi tata perilaku (DOC) terus dipertahankan, dengan semua pihak sepakat bahwa pembicaraan mengenai tata perilaku akan terus dilanjutkan dalam forum-forum ke depan sampai mencapai persetujuan.

Kedua, isu LTS memperlihatkan bahwa ASEAN mampu menyesuaikan diri dengan perkembangan geopolitik terkini. Beberapa tahun terakhir lanskap pergeseran

\footnotetext{
${ }^{48}$ Acharya, Constructing a Security Community, 69.

${ }^{49}$ Niklas Swanström, "Conflict Management and Negotiation in the South China Sea: The ASEAN Way?" (Oslo: Workshop on The South China Sea Conflict, 1999), 125.
}

kekuatan regional terlihat di Asia Tenggara. ${ }^{50}$ Pertama, kebangkitan Tiongkok. Dengan kapabilitas militer yang kuat dan kekuatan ekonomi yang cukup baik, Tiongkok semakin gencar melakukan peningkatan investasi di berbagai negara Asia Tenggara. Pada tahun 2050, Tiongkok diperkirakan menjadi kekuatan ekonomi terbesar di dunia, mengungguli AS, Jepang, dan Eropa. Kedua, berlanjutnya kehadiran militer AS di kawasan. AS memiliki kepentingan kebebasan navigasi di LTS. Kehadiran dan patroli kapal militer AS seringkali menjadi sumber konfrontasi antara AS dan Tiongkok. Sebagai contoh, pada bulan Juli 2018, Angkatan Laut AS dan Filipina melaporkan bahwa Tiongkok mengusir dan mengancam kapal dan pesawat militer Filipina yang beroperasi di LTS. Meski mengetahui hal itu, Komodor AS Clay Doss mengatakan bahwa operasi militer AS di Asia-Pasifik tidak terpengaruh oleh

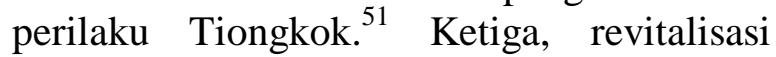
peran keamanan Jepang. Tensi yang dinamis di bagian utara dan potensi konflik di bagian selatan membuat Jepang melakukan kebijakan keamanan jangka panjang yang menekankan perangkat militer modern. Pada tahun 2012, Jepang untuk pertama kalinya menerbitkan dokumen strategi keamanan nasional dan panduan program pertahanan nasional yang akan diimplementasikan dalam ekspansi angkatan laut dan memperkuat patroli dan kapabilitas udara Jepang. Sebagai konsekuensinya, Jepang melakukan kerja sama keamanan dengan

\footnotetext{
${ }^{50}$ Rizal Sukma, "Negara-negara Besar, Arsitektur Regional, dan Posisi Indonesia," Jurnal Luar Negeri 26, no. 1 (2009): 47.

${ }^{51}$ Ryan Pickrell, "'Leave immediately or you will pay': China is threatening foreign ships and planes, but the US military isn't changing a thing," Business Insider, 31 Juli 2018, https://www.businessinsider.com.au/china-warnsforeign-ships-planes-to-steer-clear-of-its-islands-orpay-2018-7 (diakses pada 8 Desember 2018).
} 
negara-negara di sekitarnya. ${ }^{52}$ Keempat, perkembangan India. Dengan Act East Policy (AEP), India terus mendekat secara ekonomi dan keamanan kepada kawasan Asia Tenggara. Kerja sama perdagangan dan investasi India beranjak pada kerja sama politik dan keamanan. Oleh karena itu, India memiliki kepentingan agar LTS menjadi kawasan yang stabil dan kebebasan navigasi terus terjamin. Di kawasan Asia Tenggara, India menjalin kerja sama dengan Vietnam, AS, dan Jepang. ${ }^{53}$

Untuk menyesuaikan diri dengan perkembangan tersebut, ASEAN menjadi rekanan utama dari kawasan yang lebih besar seperti Asia Timur dan Asia-Pasifik. ASEAN menyediakan platform bagi aktoraktor dalam dan luar kawasan untuk mengartikulasikan kepentingan mereka dalam berbagai institusi multilateral yang dipimpin ASEAN. Forum-forum pertemuan tersebut, diantaranya, ARF, Pertemuan Menteri Luar Negeri negara-negara ASEAN, KTT ASEAN, serta forum informal seperti MPCSCS. Dalam bidang ekonomi, ASEAN membentuk ASEAN+3, mengadakan pertemuan menteri pertahanan, serta East Asian Summit (EAS). Meski tidak menjadi badan supranasional seperti Uni Eropa yang memiliki peraturan yang ketat dan mengikat, termasuk belum adanya tata berperilaku yang mengikat di LTS, ASEAN mampu mempertahankan sentralitas atau penghubung dalam arsitektur organisasi kawasan. Kemampuan ASEAN menjadi sentral dalam menjalankan kerja sama regional disebabkan oleh tiga hal.$^{54}$ Pertama, ASEAN diuntungkan oleh rivalitas di antara negara-negara besar yang mencegah mereka

\footnotetext{
52 Bhubhindar Singh, "The Development of Japanese Security Policy: A Long-Term Defensive Strategy," Asia Policy, no. 19 (2015): 51-52.

${ }^{53}$ Ulises Granados, "India's Approaches to the South China Sea: Priorities and Balances," Asia \& the Pacific Policy Studies 5, no. 1 (2017): 123.

${ }^{54}$ Heng, The "ASEAN Way", 6.
}

untuk membentuk badan keamanan multilateral di kawasan. Ketidakmampuan Tiongkok dan Jepang untuk menyediakan kepemimpinan yang kooperatif menyebabkan ASEAN menjadi instrumen penting untuk menjadi penghubung kerja sama regional. Kedua, ASEAN mampu membuat model regionalisme minimal yang menyediakan instrumen kerja sama informal yang bisa diterima oleh Tiongkok, Jepang, AS, dan negara besar luar kawasan lainnya. Ketiga, norma-norma ASEAN sangat cocok dengan norma yang telah ada sebelumnya, seperti Five Principles of Peaceful Coexistence yang diartikulasikan Tiongkok dan India pada tahun 1953 dalam kerangka Gerakan Non-Blok. Prinsip-prinsip tersebut yaitu saling menghormati kedaulatan teritorial, non-agresi, non-intervensi, keuntungan bersama, dan hidup berdampingan secara damai.

Ketiga, cara-cara ASEAN memastikan bahwa Tiongkok selalu memperbarui komitmen damai dan pada akhirnya menyepakati draf tunggal teks negoisasi tata perilaku di LTS. Pada tahun 1994, Direktur Asia Kementrian Luar Negeri Tiongkok Wang Yingfan dalam forum MPCSCS menyatakan bahwa Tiongkok siap untuk mengadakan kerja sama eksplorasi dan setuju bahwa masalah LTS harus diselesaikan secara damai. ${ }^{55}$ Dalam ARF ke8 tahun 2001 di Hanoi, Menteri Luar Negeri Tiongkok kembali menegaskan prioritas pilihan Tiongkok untuk membangun sikap bersahabat dengan negara tetangga. ${ }^{56}$ Pernyataan damai dan bersahabat kembali muncul, ketika Perdana Menteri Lie Keqiang

\footnotetext{
55 John W. Garver, "China's Push through the South China Sea: The Interaction of Bureaucratic and National Interests," The China Quarterly, no. 132 (1992).

56 Thammy Evans, "The PRC's Relationship with the ASEAN Regional Forum: Realpolitik, Regime Theory or a Continuation of the Sinic Zone of Influence System?" Modern Asian Studies 37, no. 3 (2003).
} 
Sengketa Laut Tiongkok Selatan:

Sebuah Catatan Keberhasilan?

dalam East Asian Summit 2015 menyatakan bahwa "China does not want the SCS to become a source of tension for the region". Tiongkok juga bersedia berbicara dengan negara-negara kawasan lain "to maintain the freedom of navigation and overflight". 57 Dalam hal ini, meski memiliki kelemahan karena tidak bisa menghentikan perilakuperilaku konfrontasi yang kadang dilakukan Tiongkok di LTS, ASEAN Way mendorong Tiongkok untuk terus menyatakan diri mendukung proses damai dan terlibat dalam konsultasi mengenai isu LTS dalam forumforum regional maupun multilateral. Pada 3 Agustus 2018, para menteri luar negeri negara ASEAN dan Tiongkok akhirnya menyetujui draf tunggal teks negosiasi tata berperilaku di LTS. Draf tunggal tersebut akan menjadi dasar bagi adopsi kode tata berperilaku di LTS. Teks negosiasi menyebutkan bahwa TAC, yang merupakan sumber dokumen ASEAN Way, masih merupakan pedoman penyelesaian masalah di kawasan. Oleh karena itu, draf tunggal tidak menyertakan pihak ketiga di luar ASEAN dan Tiongkok sebagai penandatangan. ${ }^{58}$ Menteri Luar Negeri Tiongkok Wang Yi menyatakan bahwa kesepakatan draf tunggal membuktikan bahwa Tiongkok dan negara-negara ASEAN mampu mempertahankan perdamaian dan stabilitas di LTS dan menghasilkan aturan regional bersama. ${ }^{59}$

\footnotetext{
${ }^{57}$ Martinez-Barcelon, "The ASEAN way."

${ }^{58}$ Carl Thayer, "A Closer Look at the ASEAN-China Single Draft South China Sea Code of Conduct," The Diplomat, 3 Agustus 2018,

https:/thediplomat.com/2018/08/a-closer-look-at-theasean-china-single-draft-south-china-sea-code-ofconduct/ (diakses 10 Desember 2018).

${ }^{59}$ MOFA of the PRC, "Wang Yi: The Agreement of the Single Draft Negotiating Text of the Code of Conduct (COC) in the South China Sea Proves that China and the Countries of the Association of Southeast Asian Nations (ASEAN) Are Capable of Reaching Regional Rules Adhered to by All,"
}

\section{Kesimpulan}

Cara-cara ASEAN ketika menghadapi kasus kontroversial di Asia Tenggara seringkali menimbulkan banyak kritik. ASEAN sering dianggap kurang optimal dalam menyelesaikan persoalan besar di kawasan. Hal itu tidak bisa dilepaskan dari harapan terhadap ASEAN agar mengambil peran multilateral yang lebih besar. Dinamika regional baru yang muncul bersamaan dengan isu LTS merupakan salah satu ujian untuk membuktikan bahwa ASEAN merupakan organisasi yang kuat dan efektif. Meskipun tidak menghasilkan kemajuan yang cepat dan drastis, ASEAN dengan transformasi ASEAN Way berjalan ke arah yang positif dalam merespon isu LTS. Tidak hanya itu saja, dalam perjalanan ASEAN, ASEAN Way berpeluang untuk menyesuaikan diri dengan tantangan baru. ASEAN sebagai organisasi regional telah merespon perubahan kekuatan regional dengan tepat. Untuk langkah ke depan, dalam menangani konflik LTS, ASEAN butuh bersatu sebagai satu unit untuk bernegosiasi dengan pihak luar dan membentuk sistem keamanan kolektif antara ASEAN dan Tiongkok. Mekanisme yang harus dipastikan dan dipertahankan oleh ASEAN dan Tiongkok adalah desakan Tiongkok mengenai non-intervensi dari pihak-pihak yang tidak terlibat dan kontinuitas sentralitas ASEAN dalam upaya penyelesaian sengketa. ASEAN perlu untuk terus waspada sekaligus terus mendorong penyelesaian isu LTS karena kegagalan dalam mempertahankan stabilitas dalam isu LTS akan memengaruhi kawasan yang lebih luas selain Asia Tenggara, misalnya kawasan Asia Timur dan Asia-Pasifik.

https://www.fmprc.gov.cn/mfa_eng/zxxx_662805/t15 83333.shtml (diakses pada 20 Desember 2018). 


\section{DAFTAR PUSTAKA}

Acharya, Amitav. Constructing a Security Community in Southeast Asia: ASEAN and The Problem of Regional Order, $2^{\text {nd }}$ ed. New York: Routledge, 2009.

ASEAN. ASEAN Plus Three Documents Series 2011-2015. Jakarta: The ASEAN Secretariat, 2016.

ASEAN. Chairman's Statement of the $16^{\text {th }}$ ASEAN-China Summit. Bandar Seri Begawan, Brunei Darussalam, 2013b.

ASEAN. Bali Declaration on ASEAN Community in a Global Community of Nations "Bali Concord III". Jakarta: ASEAN Secretariat, 2011.

ASEAN. Handbook of Selected ASEAN Political Documents. Jakarta: ASEAN Secretariat, 2003.

ASEAN. "About The ASEAN Regional Forum." aseanregionalforum.asean.org/about.html (diakses pada 2 Januari 2019).

ASEAN. "Declaration of ASEAN Concord, Bali, Indonesia, 24 February 1976." http://asean.org/?static_post=declaration-of-asean-concord-indonesia-24-february-1976 (diakses pada 2 Januari 2019).

ASEAN. "Chairman's Statement of the 11th ASEAN-China Summit Singapore, 20 November 2007." http://asean.org/?static_post=chairman-s-statement-of-the-11thasean-china-summit-singapore-20-november-2007 (diakses pada 2 Januari 2019).

ASEAN. "Chairman's Statement of the 17th ASEAN Summit." http://asean.org/?static_post=chairman-s-statement-of-the-17th-asean-summit (diakses pada 2 Januari 2019).

BBC.“ Klaim Cina di Laut Cina Selatan 'tak punya landasan hukum'”. BBC News, 12 Juli 2016.

https://www.bbc.com/indonesia/dunia/2016/07/160712_dunia_putusan_lautcinaselatan (diakses pada 4 Mei 2019).

Beeson, Mark. "What's the point of Asean?" Asia Times, 1 Mei 2017. http://www.atimes.com/whats-point-asean/ (diakses pada 29 Desember 2018).

Bower, Ernest. "18th ASEAN Regional Forum in Bali, Indonesia." Center for Strategic \& International Studies, 1 Agustus 2011. https://www.csis.org/analysis/18th-aseanregional-forum-bali-indonesia (diakses pada 29 Desember 2018).

Busse, Niklas. "Constructivism and Southeast Asian security." The Pacific Review 12, no. 1 (1999): 39-60.

Caballero-Anthony, Mely. "Mechanism of Dispute Settlement: The ASEAN Experience." Contemporary Southeast Asia, 20, no. 1 (1998): 38-66.

Darmawan, Arief Bakhtiar \& Mahendra, Lady. "Isu Laut Tiongkok Selatan: Negara-negara ASEAN Terbelah Menghadapi Tiongkok." Jurnal Global \& Strategis 12, no. 1 (2018): 79-100.

Deplu RI. Hubungan Kemitraan ASEAN-China. Jakarta: Departemen Luar Negeri Republik Indonesia, 2011.

Djalal, Hasjim. "South China Sea: Contribution of 2nd Track Diplomacy/Workshop Process to Progressive Development of Regional Peace and Cooperation." Manila, Filipina, 1617 Oktober 2011.

Djalal, Hasjim. "Managing Potential Conflicts in the South China Sea: Lessons Learned," dalam Maritime Regime Building, diedit oleh Mark J. Valencia, 87-92. Britain: Kluwer Law International, 2001.

Djalal, Hasjim, et.al. "Usaha-Usaha Mengalihkan Potensi Konflik di Laut Cina Selatan Menjadi Potensi Kerjasama." Proyek Penelitian dan Pengembangan Politik Luar 
Arief Bakhtiar Darmawan, Hestutomo Restu Kuncoro | Penggunaan ASEAN Way dalam Upaya Penyelesaian Sengketa Laut Tiongkok Selatan: Sebuah Catatan Keberhasilan?

Negeri Yayasan Pusat Studi Asia Tenggara dengan Badan Penelitian dan Pengembangan Departemen Luar Negeri Republik Indonesia, Jakarta: Yayasan Pusat Studi Asia Tenggara, 1995.

Evans, Thammy. "The PRC's Relationship with the ASEAN Regional Forum: Realpolitik, Regime Theory or a Continuation of the Sinic Zone of Influence System?" Modern Asian Studies 37, no. 3 (2003): 737-763.

Firman, Tony. "Disfungsi ASEAN dan Kegagapannya Merangkul Asia Tenggara." Tirto.id, 8 Agustus 2018. https://tirto.id/disfungsi-asean-dan-kegagapannya-merangkul-asiatenggara-cP9S (diakses pada 29 Desember 2018).

Fujisawa, Iwao. "The Use and Abuse of the "ASEAN Way"." Discussion Papers, Chiba: Center for Relational Studies on Global Crises, Chiba University, 2017.

Garver, John W. "China's Push through the South China Sea: The Interaction of Bureaucratic and National Interests." The China Quarterly, no. 132 (1992): 999-1028.

Goh, Gillian. "The 'ASEAN Way' Non-Intervention and ASEAN's Role in Conflict Management." Stanford Journal of East Asian Affairs 3, no. 1 (2003): 113-118.

Granados, Ulises. "India's Approaches to the South China Sea: Priorities and Balances." Asia \& the Pacific Policy Studies 5, no. 1 (2017): 122-137.

Haryanto, Agus. \& Pasha, Isman. Diplomasi Indonesia: Realitas dan Prospek. Yogyakarta: Pustaka Ilmu, 2016.

Heng, Pek Koon. "The "ASEAN Way" and Regional Security Cooperation in the South China Sea." European University Institute (EUI) Working Paper: Robert Schuman Centre for Advanced Studies, 2014.

Jennings, Ralph. "Four Countries Plan Resistance to China in a Disputed Asian Sea." VoA News, 5 Februari 2018. https://www.voanews.com/a/countries-push-for-joint-navalexercises-in-south-china-sea/4239171.html (diakses pada 30 Desember 2018).

Katsumata, Hiro. "Reconstruction of Diplomatic Norms in Southeast Asia: The Case for Strict Adherence to the ASEAN Way." Contemporary Southeast Asia: A Journal of International and Strategic Affairs 25, no. 1 (2003): 104-121.

Kemlu RI. ASEAN: Selayang Pandang. https://www.kemlu.go.id/Documents/ASEAN/ASP_2012_Edisi_20.pdf.

Kivimäki, Timo. "The Long Peace of ASEAN." Journal of Peace Research 38, no. 1 (2001): $5-25$.

Martinez-Barcelon, Aleja. "The ASEAN way in the South China Sea disputes." PacNet 57(A), Hawai: Pacific Forum CSIS, 2016. https://www.csis.org/analysis/pacnet-57aasean-way-south-china-sea-disputes (diakses pada 30 Desember 2018).

MOFA of the PRC. Wang Yi: The Agreement of the Single Draft Negotiating Text of the Code of Conduct (COC) in the South China Sea Proves that China and the Countries of the Association of Southeast Asian Nations (ASEAN) Are Capable of Reaching Regional Rules Adhered to by All. https://www.fmprc.gov.cn/mfa_eng/zxxx_662805/t1583333.shtml (diakses pada 30 Desember 2018).

Mogato, Manuel, Martina, Michael, \& Blanchard, Ben. "ASEAN deadlocked on South China Sea, Cambodia blocks statement." Reuters, 25 Juli 2016. https://www.reuters.com/article/us-southchinasea-ruling-asean/asean-deadlocked-on- 
Arief Bakhtiar Darmawan, Hestutomo Restu Kuncoro | Penggunaan ASEAN Way dalam Upaya Penyelesaian Sengketa Laut Tiongkok Selatan: Sebuah Catatan Keberhasilan?

south-china-sea-cambodia-blocks-statement-idUSKCN1050F6 (diakses pada 2 Januari 2019).

Pickrell, Ryan. "'Leave immediately or you will pay': China is threatening foreign ships and planes, but the US military isn't changing a thing." Business Insider, 31 Juli 2018. https://www.businessinsider.com.au/china-warns-foreign-ships-planes-to-steer-clearof-its-islands-or-pay-2018-7 (diakses pada 2 Januari 2019).

Pompeo, Michael R. Remarks on "America's Indo-Pacific Economic Vision”. Washington, DC: Secretary of State, 2018.

Renyoet, Claudia Conchita. "Diplomasi Informal sebagai Pendekatan dalam Proses Penyelesaian Konflik Laut Cina Selatan." Tesis, Yogyakarta: Universitas Gadjah, 2012.

Reus-Smit, Christian. "Constructivism," dalam Theories of International Relations, diedit oleh S. Burcholl, et al., 188-212. New York: Palgrave Macmillan, 2005.

Severino, Rudolfo. "ASEAN and the South China Sea." Security Challenges 6, no. 2 (2010): 37-47.

Severino, Rudolfo. Southeast Asia in Search of an ASEAN Community. Singapore: Institute of Southeast Asian Studies, 2006.

Singh, Bhubhindar. "The Development of Japanese Security Policy: A Long-Term Defensive Strategy." Asia Policy, No. 19 (2015): 49-64.

Sukma, Rizal. "Negara-negara Besar, Arsitektur Regional, dan Posisi Indonesia." Jurnal Luar Negeri 26, no. 1 (2009): 45-59.

Swanström, Niklas. Conflict Management and Negotiation in the South China Sea: The ASEAN Way? Oslo: Workshop on The South China Sea Conflict, 1999.

Thayer, Carl. "A Closer Look at the ASEAN-China Single Draft South China Sea Code of Conduct." The Diplomat, 3 Agustus 2018. https://thediplomat.com/2018/08/a-closerlook-at-the-asean-china-single-draft-south-china-sea-code-of-conduct/ (diakses pada 3 Januari 2019).

Tobing, Dio Herdiawan. "The Limits and Possibilities of the ASEAN Way: The Case of Rohingya as Humanitarian Issue in Southeast Asia," dalam The 1st International Conference on South East Asia Studies, 2016, KnE Social Sciences, 148-174.

Weissmann, Mikael. "The South China Sea: Still No War on the Horizon." Asian Survey 55, no. 3 (2015): 596-617.

Weissmann, Mikael. "Why is there a relative peace in the South China Sea?" dalam Entering Uncharterd Waters? ASEAN and The South China Sea Dispute, diedit oleh Pavin Chachavalpongpun, 36-64. Singapore: Institute of Southeast Asian Studies, 2014.

Woon, Walter. "Dispute Settlement the ASEAN Way." Singapore: Center for International Law, 2012.

Yukawa, Taku. "The ASEAN Way as a symbol: an analysis of discourses on the ASEAN Norms." The Pacific Review 31, no. 3 (2018): 298-314. 